\title{
Apodinium floodi n. sp., a dinoflagellate (Dinoflagellata: Apodinidae) ectoparasitic on Oikopleura labradoriensis (Urochordata: Larvacea)
}

\author{
Norman McLean ${ }^{1}$, Charles P. Galt ${ }^{2}$ \\ ${ }^{1}$ Department of Biology, San Diego State University, San Diego, California 92182-0057, USA \\ ${ }^{2}$ Department of Biology, California State University, Long Beach, California 90840-3702, USA
}

\begin{abstract}
The ectoparasitic dinoflagellate Apodinium floodi n.sp. is reported from the pelagic tunicate Oikopleura labradoriensis (Phylum Chordata, Subphylum Urochordata, Class Larvacea). The trophozoite of $A$. floodi, which reaches $890 \mu \mathrm{m}$ in length, is encased by a membranous envelope and is attached to the tail of the host. Divisions of the young trophozoite produce an elongate, single file of sporogenic cells. Later, divisions perpendicular to the long axis of the trophozoite occur in distal sporogenic cells, and ultimately dinospores are produced. An attachment organelle or peduncle penetrates the host's musculature, crosses the hemocoel and reaches the notochord; at that level, 2 principal rhizoids, each provided with a condyle, a dense lining, and an absorptive outer layer of tubules, diverge from the peduncle and invade the outer region of the notochord. Tumor-like growths in the lumen of the notochord, and other abnormal proliferations of the host's cells, occur
\end{abstract}

\section{INTRODUCTION}

Apodinium Chatton, 1907 (Chatton 1907), a genus of dinoflagellates ectoparasitic on larvacean (= appendicularian) tunicates, has been reported only from European marine waters (Cachon \& Cachon 1973). We have observed an apodinid, which we describe as a new species, on the larvacean tunicate Oikopleura labradoriensis Lohmann, 1892, from northwest Washington, USA.

\section{MATERIALS AND METHODS}

Specimens of Oikopleura labradoriensis bearing from 1 to 4 apodinids on their tail were collected from surface water near the Friday Harbor Laboratories, San Juan Island, Washington, USA, during the periods January through April 1989 and 1990. Parasites were examined with brightfield microscopy (BM) or with Nomarski differential interference contrast microscopy (designated below as Nomarski), or were fixed and prepared for light microscopy (LM), transmission electron microscopy (TEM) or scanning electron micro- scopy (SEM). For LM and TEM, trophozoites were fixed for from $1 \mathrm{~h}$ to $8 \mathrm{~d}$ in (1) $3 \%$ glutaraldehyde (Ladd) in $0.1 \mathrm{M}$ phosphate buffer $(\mathrm{pH} 7.3)$ with or without $0.35 \mathrm{M}$ sucrose (room temp. or $4{ }^{\circ} \mathrm{C}$ ), or (2) $2 \%$ glutaraldehyde and $1.7 \%$ formaldehyde in $0.03 \mathrm{M}$ phosphate buffer with $0.3 \mathrm{M}$ sucrose and $0.1 \mathrm{M}$ EGTA, rinsed briefly in buffer with or without sucrose, and postfixed on ice in $1 \%$ osmium tetroxide in $0.1 \mathrm{M}$ phosphate buffer ( $\mathrm{pH}$ 7.3) with or without $0.35 \mathrm{M}$ sucrose. Specimens for sectioning were dehydrated in an ethanol series followed by propylene oxide and embedded in LX-112 (Ladd), or in an acetone series and embedded in Spurr's medium (Ladd). For LM, $1 \mu \mathrm{m}$ sections were stained in $1 \%$ methylene blue in $1 \%$ borax. For TEM, silver sections were stained in saturated uranyl acetate for $12 \mathrm{~min}$ and in $0.1 \%$ lead citrate for $3 \mathrm{~min}$, or in lead citrate alone, or were not stained, and were examined with a Philips 300 electron microscope. For SEM, specimens were fixed in $2 \%$ osmium tetroxide in distilled water, dehydrated in acetones, and critical point-dried in $\mathrm{CO}_{2}$. They were attached to stubs with Double Stick Scotch Tape, coated with Au/Pd and examined with a JEOL JSM-35 scanning electron microscope. 


\section{RESULTS}

\section{Apodinium floodi n.sp.}

Diagnosis. Trophozoites reach $890 \mu \mathrm{m}$ in length. including dinospores yet to be liberated. Divisions of young trophozoite produce sporogenic cells in a single file; further divisions produce a mass of girdled dinospores that are provided with dinokaryotic chromosomes and trichocysts of dinoflagellate type, and that are liberated apically through a rupture in encompassing membranous envelope. Relatively narrow peduncle originates at sporogenic cytoplasm; diameter increases distally, then decreases gradually until host epidermis and muscle plate are penetrated; peduncle crosses host hemocoel, often accompanied by tube of host cytoplasm, until notochord is reached; within host, peduncle with thin septum that separates lumina of 2 thickly walled elements; lumen of each element continuous with that of principal rhizoid that invades outer region of notochord, between basement membrane and microfibrils, and later branches; rhizoids with dense inner layer, and absorptive outer layer of tubules ( $=$ villosities) on both lateral and medial surface; each principal rhizoid with dense, homogeneous condyle. Tumor-like growths in notochordal lumen, and abnormal cytoplasmic proliferations adjacent to rhizoids. Host, Oikopleura labradoriensis Lohmann, 1892 (Phylum Chordata, Subphylum Urochordata, Class Larvacea).

Type locality. Marine. Surface waters near San Juan Island, Washington, USA, Lat. $48^{\circ} 32^{\prime} \mathrm{N}$, Long. $123^{\circ}$ $00^{\prime} \mathrm{W}$.

Type material. Syntypes: trophozoites embedded in epoxy resin have been deposited at the National Protozoan Type Collection, National Museum of Natural History, Smithsonian Institution, Washington, D.C., USA, and given the registration numbers: USNM 42349,42350 and 42351 .

Etymology. The species is named in recognition of Professor Per R. Flood, University of Bergen, who collected many of the organisms used in this study, and who has made major contributions to our understanding of feeding in larvacean tunicates.

\section{Morphology and activities of the parasite}

As many as $70 \%$ of the Oikopleura labradoriensis collected during a tidal period were infected (e.g. on 17 Jan 1990, 21 of 30 hosts bore Apodinium floodi). The trophozoites (Figs. 1 \& 2), which reached $890 \mu \mathrm{m}$ in length including unliberated dinospores, were

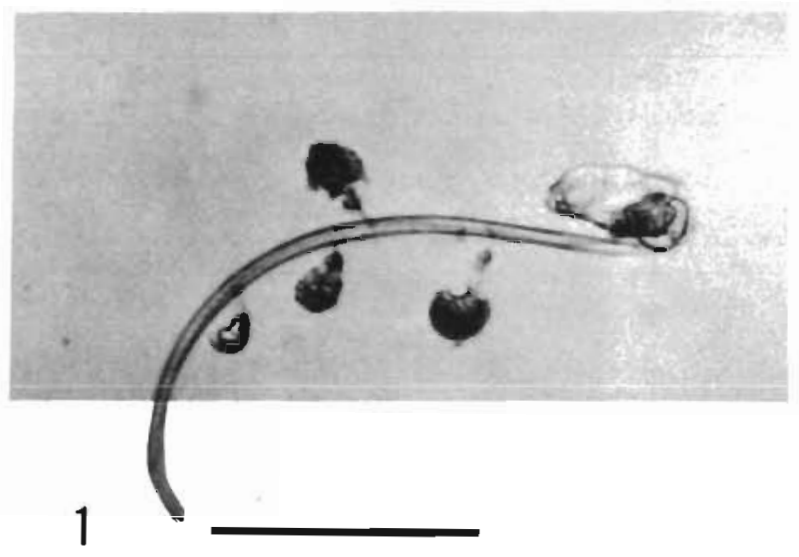

Fig. 1. Oikopleura labradoriensis with 4 trophozoites of Apodinium floodi attached to tail. BM; scale bar ca $2 \mathrm{~mm}$

attached to the tail of $O$. labradoriensis, usually near the midline close to the tip, but frequently more proximally on the tail. Without exception the parasites were attached to the tail within the width of the muscle plates and had their rhizoids attached to the notochord. Young specimens were unicellular; in older forms, a linear array of sporogenic cells arranged in a single file was produced, and provided with trichocysts characteristic of dinoflagellates. Later, the distal sporogenic cells divided perpendicularly to the long axis of the trophozoite; ultimately, further divisions produced a large mass of dinospores (Figs. 2 \& 3) that, in one instance, was $560 \mu \mathrm{m}$ in length. Dinospores were ca $17 \mu \mathrm{m}$ in length and $12 \mu \mathrm{m}$ in width; they bore trichocysts (Fig. 4), dinokaryotic chromosomes (Fig. 5), in a few cases rudimentary flagella, and were provided with a central constriction that, we suggest, rep-

Figs. 2 to 8. Apodinium floodi on Oikopleura labradonensis. Fig. 2. Trophozoite attached to tail ( $\mathrm{t}$ ) of host by peduncle (p). Above: mass of forming dinospores, only the lower portion of which is encased by envelope (e); note sporogenic cells (e.g. arrow) arranged in a linear array; arrowhead: unidentified material. SEM; scale bar $100 \mu \mathrm{m}$. Fig. 3. Mass of forming dinospores, upper portion of which is free from the envelope (e) of the trophozoite. SEM; scale bar $20 \mu \mathrm{m}$. Fig. 4 . Dinospore. Arrowhead: trichocyst; arrow: chromosome. TEM; scale bar $5 \mu \mathrm{m}$. Fig. 5. Dinokaryotic chromosome within nucleus of forming dinospore. TEM; scale bar $0.5 \mu \mathrm{m}$. Fig. 6. Young trophozoite enclosed within envelope (e). Note peduncle originating at sporogenic cytoplasm; at right: portion of an older trophozoite. Nomarski; scale bar $50 \mu \mathrm{m}$. Fig. 7 . Tail of host penetrated by dense parasitic peduncle, the septum of which is visible. Majority of trophozoite is not in plane of figure; $\mathrm{H}$ : tube of host cytoplasm accompanying peduncle as it crosses hemocoel $(h)_{i} r$ principal rhizoid applied to notochord; arrowhead: tumor-like structure within lumen of notochord; m: musculature of tail. $\mathrm{LM}_{i}$ scale bar $50 \mathrm{\mu m}$. Fig. 8. Unstained material. Peduncle within tube of host cytoplasm (H); lp: peduncular lumen; arrowhead: septum; h: hemocoel. TEM; scale bar $2 \mu \mathrm{m}$ 

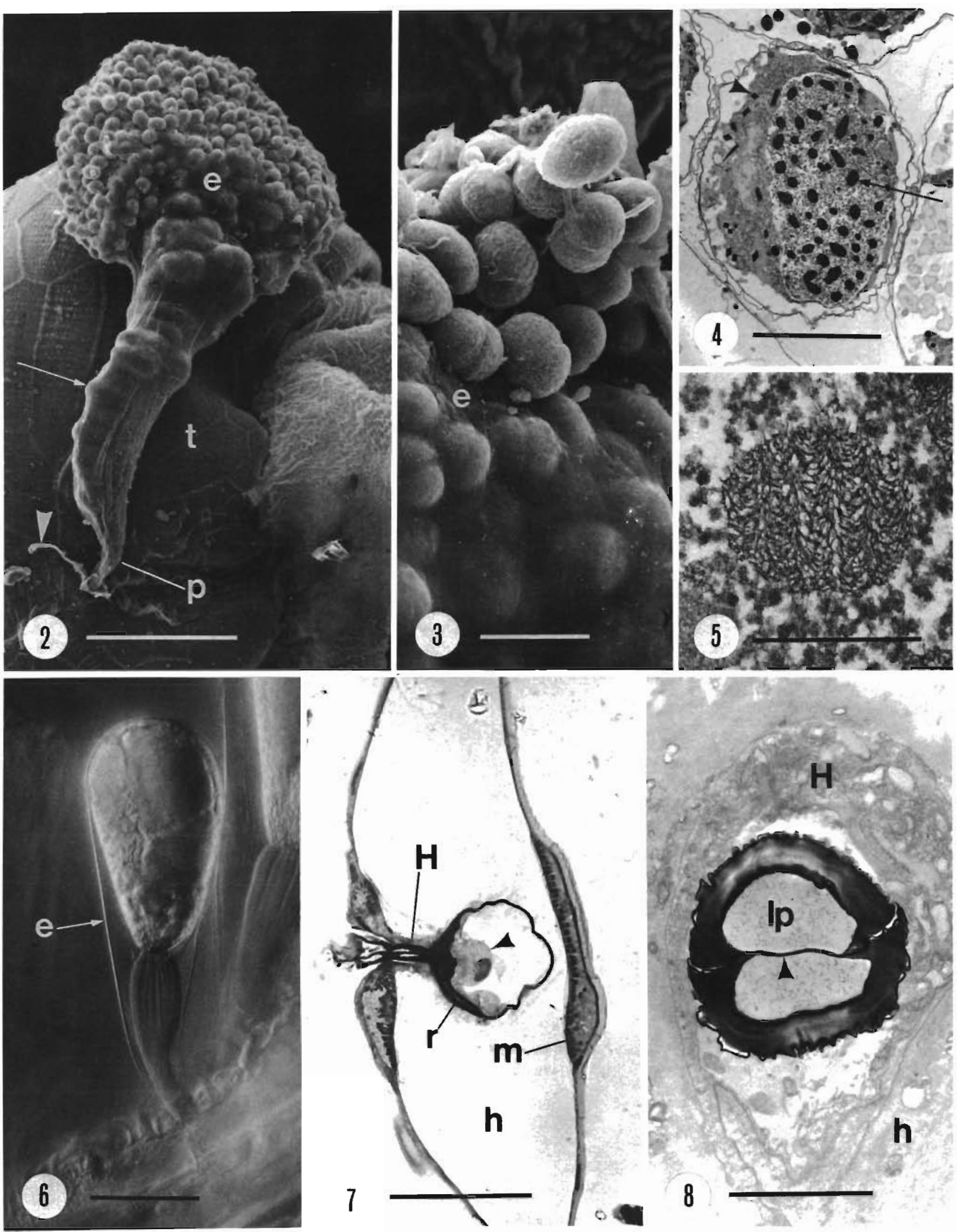

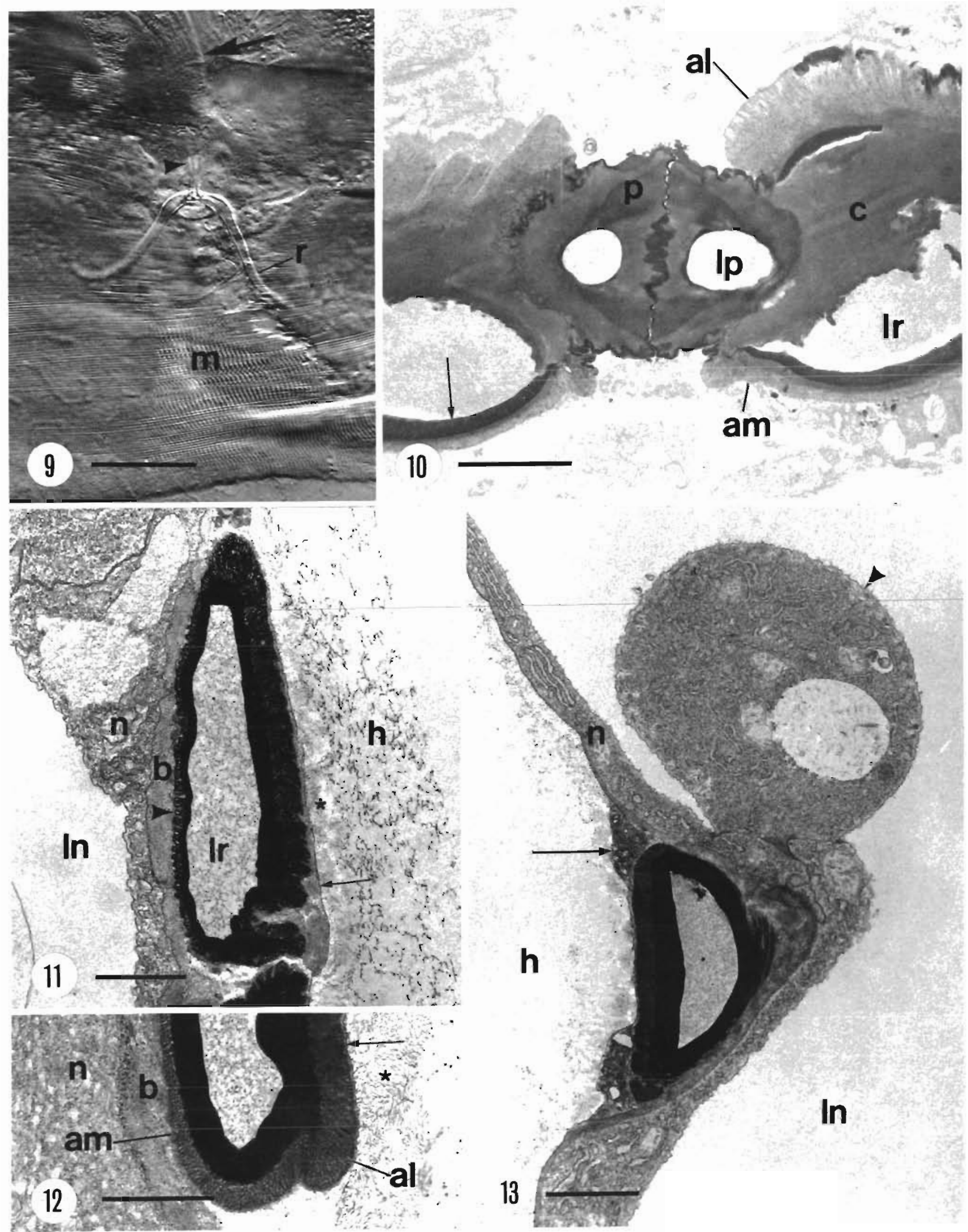
resented the girdle typical of free-living dinoflagellates.

A single, membranous envelope, which in large specimens was broken apically in the region of dinospore production, bounded each trophozoite (Figs. 2, 3 \& 6). Except for small fragments of unidentified material (Fig. 2) that may have been a remnant of the envelope of a young stage, there was no indication that the envelope periodically was supplanted by another. The attachment organelle or peduncle originated at the sporogenic cytoplasm, where its diameter was much less than that of the envelope (Fig. 6). Distal to the point of origin the peduncular diameter increased, then diminished gradually before narrowing abruptly at the host's epidermis. After passing through the musculature of the tail (Fig. 7), the peduncle crossed the hemocoel, often accompanied by a tube of cytoplasm (Figs. 7 \& 8) that we interpret as a reaction of the host to the parasite. Within the host, the peduncle was composed of 2 closely apposed elements, each containing a large lumen that was continuous with the lumen of a principal rhizoid (see below). The lumina were separated from one another by a thin, distinct septum (Figs. 7 \& 8) composed of a reflection of the parasitic envelope and the thin inner wall of the 2 elements. The wall of each element, exclusive of the septal portion, was thick, and strongly electron-opaque even in unstained material. At its distal end the peduncle was applied to the notochord of the host (Fig. 7), at which point each of its elements gave rise to a principal rhizoid (Figs. 7 \& 9) that invaded the outer region of the notochord. Near the notochord, the wall of the peduncle was thickened, and the peduncular lumina were correspondingly reduced (Fig. 10). The wall of each rhizoid was composed of an electron-opaque lining, and an outer layer of closely packed tubular structures (Figs. 10,11 \& 12) that will be referred to here as the absorptive layer. Adjacent to the peduncle, the lumen of each rhizoid was partially occluded by an electronopaque substance or condyle (Fig. 10) that was distinct from both the peduncular wall and the lining of the rhizoid and that was relatively homogeneous and not provided with fine, dense lines. The rhizoidal lumen usually contained a finely granular substance (Fig. 11). Terminally, the principal rhizoids branched and produced quite fine rhizoids.

The notochordal wall of Oikopleura labradoriensis was composed of a single layer of epithelial cells (Fig. 11), the height of which was variable; usually present was a thick, fibrous basement membrane, the basal boundary of which usually appeared as a thin, dense membrane (Figs. 11 \& 12). From this thin membrane there arose a layer of fine microfibrils (Fig. 12) that projected into the host's hemocoel. The parasitic principal rhizoids, that displayed flattened profiles in sections, did not invade the cytoplasm of the notochordal cells; instead, they were found between the notochordal basement membrane and the thin membrane that served as a base for the microfibrils. The tubules (termed villosities by Cachon \& Cachon 1973) of the rhizoidal absorptive layer were much taller on the lateral surface of the rhizoid (i.e. the side facing the microfibrils and the hemocoel) than on the medial surface (i.e. the side adjacent to the basement membrane) (Figs. 10 \& 12).

Occasionally seen within the lumen of the notochord were large, tumorlike structures (Figs. 7 \& 13) that appeared to have been produced by the cells of the notochord. These growths were found only near a rhizoid, and are presumed to be a reaction to the presence of the parasite. Also seen were abnormal cytoplasmic proliferations (Fig. 13) adjacent to both principal and fine rhizoids, between the basement membrane and the notochordal microfibrils. Inward reflections of the notochordal wall in the presence of a rhizoid (Fig. 13) occasionally occurred.

\section{DISCUSSION}

European larvacean tunicates are parasitized by 4 described species of the genus Apodinium (Cachon \& Cachon 1973, 1987). A. floodi, while clearly an apodinid, differs in a number of morphological features

Figs. 9 to 13. Apodinium floodi on Oikopleura labradoriensis. Fig. 9. Principal rhizoids (r) branching from terminal region of peduncle. Arrowhead: peduncle within host hemocoel; arrow: peduncle external to host; m: musculature of host tail; notochord is not discernible. Nomarski; scale bar $50 \mu \mathrm{m}$. Fig. 10. Unstained material. Peduncle (p) near terminal region; lp: reduced peduncular lumen; $1 \mathrm{r}$ : lumen of rhizoid; arrow: lining of rhizoid; al: lateral absorptive layer; am; medial absorptive layer; c: condyle. TEM; scale bar $2 \mu \mathrm{m}$. Fig. 11. Transverse section of rhizoid between thick notochordal basement membrane (b) and thin, dense membrane (arrow). (") Layer of notochordal microfibrils; h: hemocoel containing coagulated fibrillar substance; $n$ : notochord; in: lumen of notochord; arrowhead: tubule of medial absorptive layer; note finely granular substance in lumen (lr) of rhizoid. TEM; scale bar $1 \mu \mathrm{m}$. Fig. 12. Portion of rhizoid between notochordal basement membrane (b) and thin dense membrane (arrow). (") Layer of notochordal microfibrils; note relatively tall tubules of lateral absorptive layer (al), and shorter tubules of medial absorptive layer $(a m) ; n$ : notochord. TEM; scale bar $1 \mu \mathrm{m}$. Fig. 13. Transverse section of rhizoid at inward reflection of notochordal wall (n). Arrowhead: tumor-like structure within lumen (ln) of notochord; arrow: abnormal cytoplasmic proliferation; 
from the species previously recognized. The presence of a single file of sporogenic cells in the proximal region of the trophozoite is characteristic of $A$. floodi, A. chattoni and $A$. rhizophorum, but not of A. mycetoides or of A. zygorhizum. As dinospores are produced by successive generations of sporogenic cells in the apodinid species previously described, the envelope of the young trophozoite is retained; the envelope of each sporogenic cell that produces dinospores also is retained, in turn, until a series of envelopes, each within the one that preceded it, is formed (Chatton 1920 Pl. 2, Figs. 22 \& 23, Pl. 3, Fig. 33; Cachon \& Cachon 1973). We did not observe $A$. floodi encased by such a series of envelopes

The habitat of Apodinium floodi most closely resembles that of A. chattoni Cachon \& Cachon, 1973 (Cachon \& Cachon 1973), parasitic on the notochord of Fritillaria pellucida Busch, 1851. The peduncle of $A$. chattoni, however, unlike that of $A$. floodi, is as broad in its proximal region as the envelope of the parasite, and narrows abruptly to the thin distal portion. The medial surface of the rhizoid of $A$. chattoni is largely devoid of an absorptive layer; that surface in $A$. floodi is provided with discrete tubules. In both species, the lateral rhizoidal surface is covered by a dense mat of notochordal microfibrils; but in $A$. chattoni, unlike in $A$. floodi, the villosities are intermingled among the microfibrils. The condyles in A. chattoni are discrete lobular vesicles containing fine, dense lines that resemble cerebral convolutions in vertebrates, whereas, in $A$. floodi, the condyles are not discrete vesicles and are relatively homogeneous.

The tail of Oikopleura cophocerca Gegenbaur, 1885 is parasitized by Apodinium rhizophorum Chatton, 1912 (Chatton 1912). Its peduncle, unlike that of $A$. floodi, is not provided with a distinct septum. Although found within the tail of the host, rhizoids of $A$. rhizophorum are not associated with the notochord; they penetrate only into the musculature where their fine terminal branches ramify among the mitochondria around the muscular bundles. There is no reactionary sheath produced by the host around the finer rhizoids.

Apodnnum mycetoides Chatton, 1907 (Chatton 1907) is found on the trunk of Fritillaria pellucida. The peduncle of the parasite closely resembles that of $A$. floodi, with the elements of both being separated by a distinct septum. In addition, the cytoplasm of the host reacts to the presence of the rhizoids as in A. floodi. The 2 species differ from one another, however; the limiting membrane of the rhizoids of $A$. mycetoides is formed into numerous longitudinal folds, and no condyles are evident at the point at which its rhizoids diverge from the peduncle.

Upon the trunk of Oikopleura longicauda Vogt, 1854 , is found Apodinium zygorhizum Cachon \& Cachon,
1973 (Cachon \& Cachon 1973), a parasite quite different from $A$. floodi. Although, as with $A$. floodi, the host reacts to the presence of rhizoids of $A$. zygorhizum, the 2 elements of its peduncle lack a distinct septum, the principal rhizoids do not diverge from one another, and the condyles are provided with a wall that is greatly folded.

These morphological differences, together with the differences in host organisms, specific habitat upon the host, and geographical distribution, lead to our designation of the Oikopleura labradoriensis parasite as a new species, Apodinium floodi.

The notochord of larvacean tunicates is found in the hemocoel of the tail, and is, therefore, bathed with blood. Rhizoids of Apodinium floodi occupy, essentially, the outer surface of the notochord, with the tubules or villosities of their lateral wall being separated from the blood only by the fine microfibrils, and the very thin membrane in which the microfibrils appear to be anchored. Since a function of the extensive rhizoids evidently is the absorption of nutrients, and since the absorptive layer of the lateral rhizoidal wall is much thicker than is that of the medial wall, it is reasonable to suggest that a principal source of nutrients for $A$. floodi is the blood of the host.

Although tumor-like growths and other reactions of the host to the parasite occur, we have seen no evidence that $A$. floodi seriously interferes with swimming or other activities of the host. Both in the field and in the laboratory, parasitized Oikopleura labradoriensis swim vigorously. Since dinospores freed by the parasite within the house of the host would be captured by the food-concentrating filters, liberation of dinospores presumably occurs when the host is not within its house. Since the host leaves its house before spawning, and expires thereafter, it is possible that cytoplasmic changes concomitant with morbidity of the host stimulate the parasite to release dinospores.

Acknowledgements. We thank Dr A. O. Dennis Willows for use of research facilities at the Friday Harbor Laboratories, University of Washington. Dr Thomas E. Schroeder for assistance with transmission electron microscopy. Dr Brian Rivest and James D. Huber for assistance with scanning electron microscopy, and Prof. Per R. Flood, both for collecting and preserving many of the animals used in this study and for a critical reading of the manuscript. We are indebted to Dr Monique Cachon for valuable comments, and for her continued interest in parasitic dinoflagellates.

\section{LITERATURE CITED}

Cachon, J., Cachon, M. (1973). Les Apodinidae Chatton. Révision systèmatique rapports hote-parasite et métabolisme. Protıstologica 9: 17-33

Cachon, J., Cachon, M. (1987). Parasitic dinoflagellates. In: 
Taylor, F. J. R. (ed.) The biology of dinoflagellates. Blackwell Scientific Publ., Oxford, p. 571-610

Chatton, E. (1907). Nouvel aperçu sur les Blastodinides (Apodinium mycetoides n.g., n.sp.). C. r. Acad. Sci., Paris 144: $282-285$

Responsible Subject Editor: Dr A. K. Sparks, Seattle, Washington, USA
Chatton, E. (1912). Diagnoses préliminaires de Péridiniens parasites nouveaux. Bull. Soc. zool. Fr. 37: 85-93

Chatton, E. (1920). Les Péridiniens parasites. Morphologie, reproduction, ethologie. Arch. Zool. exp. gén. 59: 1-475

Manuscript first received: July 12, 1990

Revised version accepted: October 8, 1990 